\title{
Understanding and Enhancing Consumer Privacy Perceptions in the Cloud
}

\author{
Grace Fox
}

\begin{abstract}
The recent increase in highly publicised cloud breaches, coupled with issues surrounding transparency and control in the cloud, highlights the importance of understanding and addressing privacy in this context. The extant cloud privacy literature has a tendency to focus on technical solutions to address security and privacy together, but a small emerging body of literature acknowledges the importance of consumers' privacy perceptions in the context of cloud computing. Given the breadth of cloud applications and the situational nature of privacy, it is imperative to unpack the role of privacy in this complex domain. This chapter leverages the broader privacy literature in the Information Systems field to identify potential measures to enhance consumer privacy in the cloud context and highlights a number of paths for research to further our knowledge of consumer privacy perceptions in the various cloud contexts.
\end{abstract}

G. Fox $(\bowtie)$

Irish Institute of Digital Business, DCU Business School, Dublin, Ireland e-mail: Grace.Fox@dcu.ie

(C) The Author(s) 2021

T. Lynn et al. (eds.), Data Privacy and Trust in Cloud Computing, Palgrave Studies in Digital Business \& Enabling Technologies, https://doi.org/10.1007/978-3-030-54660-1_4 
Keywords Information privacy $\bullet$ Data privacy $\bullet$ Data protection $\bullet$ Cloud computing $\bullet$ Privacy perceptions $\bullet$ Cloud privacy $\bullet$ Cloud security

\subsection{InTRODUCTION}

The cloud offers many advantages to organisations including greater efficiency and reduced data storage costs. The market for cloud computing is forecast to continue growth in 2020 with Gartner predicting a 17\% increase to US\$266.4 billion including an increase in the value of cloud management and security services from US\$12 billion to US\$13.8 billion (Gartner 2019). Today, we see cloud applications in all industries, at the consumer application level to city-wide infrastructures. However, the increasing ubiquity of cloud computing also represents new risks, not least information security and privacy vulnerabilities. Indeed, we have seen an alarming number of high-profile cloud data breaches including the largest cloud service providers. Most recently, the open Google database exposed the personal details of 200 million people (Forbes 2020). While the cloud itself is arguably more secure than physical infrastructures, human error is often the cause of these incidents. For instance, misconfiguration of cloud databases has resulted in an estimated 196 breaches from 2018-2019, leaving 33 billion records at risk, and costing organisations an estimated US\$5 trillion over the two year period (DivvyCloud 2020). A single breach incident can be hugely costly to organisations. For example, Marriott could potentially be fined up to US\$123 million in Europe alone for its recent cloud breach, which left the details of 5.2 million people at risk (Whittaker 2020). In addition to monetary costs, it is important to consider other implications for organisations involved in such breaches such as consumer perceptions of privacy and trust in the organisation itself.

This chapter focuses on exploring how organisations can avail of the advantages offered by the cloud, while preserving consumer privacy and addressing any privacy concerns consumers may have. The chapter proceeds with an outline of the importance of privacy and security in the cloud computing context. Next, the extant literature related to privacy in this domain and the broader Information Systems (IS) field are discussed. Potential solutions for enhancing privacy perceptions in the cloud and directions to empirically explore these solutions are outlined in the final sections of the chapter. 


\subsection{Cloud Computing: Privacy and Security Issues}

Continual advances in information technology are furthering the proliferation of cloud computing in many new domains. The emergence of big data, and recent advances in areas such as IoT (Internet of Things) has massively increased the volumes of data generated by most organisations leading to an increasing need to outsource data storage to cloud service providers (Lowry et al. 2017). On the consumer level, the popularity and number of mobile applications downloaded by users has also resulted in a dependence on cloud computing to relieve storage issues; this is commonly referred to as mobile-cloud computing (Shropshire et al. 2015). This greater reliance on the cloud significantly exacerbates the risk of privacy and security incidents while also heightening the risks associated with more traditional security vulnerabilities (Lowry et al. 2017).

Privacy and security represent important challenges and potential barriers, both for organisations considering adopting and those currently relying on cloud services and cloud service providers (Alashoor 2014; Fauzi et al. 2012). A host of researchers have stressed the importance of addressing privacy in the cloud computing context (e.g. Pearson 2012; Wood 2012; Nikkhah et al. 2018). Indeed, the security and privacy issues within the cloud computing domain are far greater than those present when data is stored in a single location (Ramireddy et al. 2010). This is partly attributed to the fact that data stored in the cloud is often in unencrypted form and thus open to many vulnerabilities (Senarathna et al. 2016). Furthermore, the use of cloud computing often involves the movement of data beyond international borders requiring consideration of legal requirements in different jurisdictions while also complicating the organisation's ability to observe and manage data flows and preserve consumer privacy (Lowry et al. 2017). Privacy also represents an important consideration for cloud end users, with recent research illustrating that consumers are willing to pay to limit data collection and to ensure deletion from a cloud database (Shropshire et al. 2015).

While Chap. 3 in this book outlines the legal requirements across different jurisdictions, this chapter focuses on the consumer aspect of privacy in the cloud computing context. In addition to the undeniable importance of privacy in this context, it is important to note the intertwined nature of privacy and security within existing academic discussions. While, the focus here is on privacy, it is worthwhile to differentiate and highlight important parallels between these concepts. Both security and privacy have been 
described as human constructed abstract notions which vary according to context and other factors (Lowry et al. 2017). For the purpose of the chapter, both concepts are defined and discussed in terms of their pertinence to cloud.

\subsubsection{Information Security}

Information security refers to the preservation of the three tenets of security; the confidentiality of information, the integrity information, and the availability of information, while also considering other risks such as reliability, authenticity, and accountability (Pearson 2012; ISO 2005). In the cloud computing context, the key security vulnerabilities warranting consideration include trust, encryption, multi-tenancy, and reliability (Ramireddy et al. 2010). In addition, these vulnerabilities result in serious security risks related to data integrity, confidentiality, data loss, and data authentication (Subashini and Kavitha 2011). Research has provided some initial support for the relevance of these risks. For example, in their study of the factors impacting public sector cloud adoption in South Africa, Scholtz et al. (2016) found that data accessibility was a concern for $90 \%$ of participants and cyberattacks represented a concern for $76 \%$ for participants. Security and privacy are inextricably linked, as any security incident puts the privacy of the individual's data at risk (Sonehara et al. 2011). In addition, these security issues may lead to intangible risks or concerns such as loss in confidence of the reliability of the cloud and fears around access to personal data (Paquette et al. 2010).

\subsubsection{Information Privacy}

Privacy has been the subject of academic discourse for over two centuries in disciplines such as law, sociology and IS. Indeed, the first academic discussions of privacy are often credited to the 1890 Harvard Law Review article by Warren and Brandeis, in which they discuss privacy in terms of the need to balance individuals' rights to be free from intrusion with the information needs of society (Warren and Brandeis 1890). From a sociological perspective, the seminal definition of privacy was developed by Alan Westin (1967, p. 7), who described privacy as "the claim of individuals, groups, or institutions to determine for themselves when, how, and to what extent information about them is communicated to others." These seminal works are the building blocks of conceptualisations across 
multiple disciplines, many of which place control at the centre (Kesan et al. 2013). However, advances in technology have shifted the focus from a predominantly physical construct to a digital one, and from organisational control to an individual's control of their personal information. While discussions regarding the potential security and privacy issues within cloud computing are largely centered around adoption at an organisational level, there are many consumer issues which warrant consideration (Alashoor 2014). This chapter focuses on privacy from the IS perspective where privacy is defined as an individual's ability to personally control information about themselves and how it is disseminated (Smith et al. 1996; Bélanger and Crossler 2011).

In the cloud computing context, there are many privacy issues that organisations should consider and seek to address including issues surrounding control, unauthorised secondary use of data, and improper access (Senarathna et al. 2014; Pearson and Benameur 2010). However, the majority of extant privacy research in the cloud computing domain focuses on the technical solutions to secure data in the cloud from both design and architectural perspectives (Nikkhah et al. 2018). It is important to move beyond this and understand the role of the privacy perceptions of consumers on their adoption and use of cloud computing.

\subsection{Examining Privacy Perceptions in the Cloud}

The broader privacy literature within IS is well developed with a large number of studies conducted across multiple contexts over the past three decades. As privacy cannot be objectively measured or quantified, proxies are utilised to examine the role of privacy, with privacy concern representing the dominant approach in existing literature (Bélanger and Crossler 2011). Conceptualisations of privacy concern also differ across the myriad of existing studies with the emphasis often placed on fears around loss of privacy (Xu et al. 2011), or possible improper uses such as one's personal data being disclosed online (Son and Kim 2008). As summarized in Table 4.1 below, four scales are predominantly used to measure information privacy concerns in the IS literature (Alashoor et al. 2017). While there is an absence of agreement on the most appropriate scale, each of these scales have been rigorously tested, validated and adapted to other contexts. Furthermore, across these scales six dimensions of concern are consistently included. 
64 G. FOX

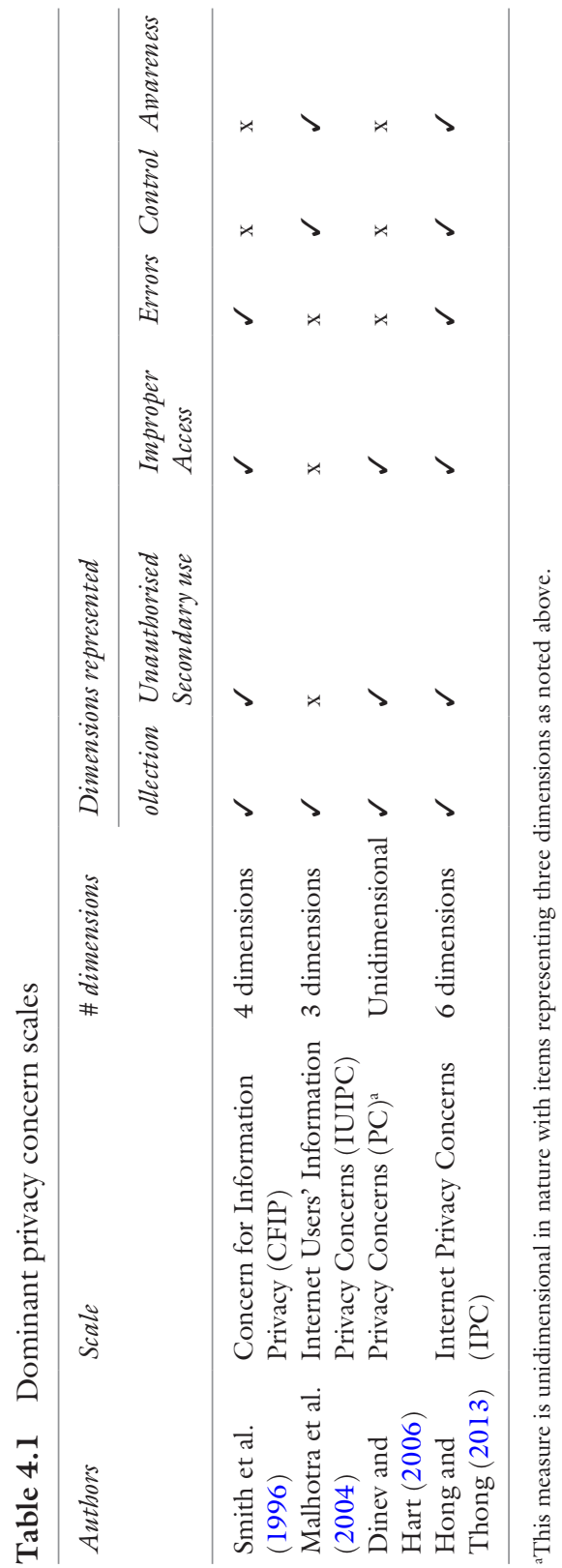


While these privacy measures are commonly deployed in other contexts, the majority of extant cloud computing privacy studies do not use validated measures of privacy concern but instead explore privacy and security issues together using open-ended questions or single-item ranking questions. For example, in a study conducted by Scholtz et al. (2016), $90 \%$ of participants rated the privacy of data as important or very important. However, two related studies adapted Dinev and Hart's (2006) PC measure (Nikkhah et al. 2018; Nikkhah and Sabherwal 2017). Validated measures of information privacy concern warrant consideration in future cloud computing privacy studies to provide a more nuanced view of privacy in the cloud and to allow comparisons to be drawn with privacy concerns in other contexts. Indeed, many of these dimensions represent core privacy issues highlighted by cloud researchers (e.g. Pearson and Benameur 2010). However, the extant empirical literature has not yet encompassed these dimensions. The relevance of these dimensions is briefly noted in terms of understanding consumers' perceptions of privacy.

The collection dimension focuses on individuals' concerns regarding an organisation's collection and storage of a great deal of their personal information (Smith et al. 1996). Consumers often lack an awareness of how their data stored in the cloud is used and disseminated, and whether it is used for purposes other than those it was collected for (Nikkhah et al. 2018). For example, in some cases such as Google Drive or Dropbox, the storage of personal information in the cloud is the primary purpose of the service and therefore use is transparent. Other applications such as those in the Internet of Things (IoT) domain, are less clear. Data may be stored on the device, somewhere locally, or in the cloud, or a combination of one or more these. Consumers may not even be aware of where data is stored. It is important to explore whether cloud data storage generates consumer privacy concern and how this differs across applications and information types.

The Unauthorised Secondary Use dimension focuses on individuals' concerns that information collected for one purpose is subsequently used for a secondary purpose without obtaining the individual's permission (Smith et al. 1996). Consumer perceptions of unauthorised secondary use in the cloud context are highlighted in extant research (Pearson and Benameur 2010). The Improper Access dimension covers individuals' concerns that an organisation does not have the measures in place to prevent unauthorised individuals from accessing their information (Smith et al. 1996). The recent media coverage around large cloud data breaches 
may heighten consumer awareness of potential improper access to their data stored in the cloud, and consequently, increase their concerns around such access. The Errors measure of concern focuses on individuals' concerns that the organisation storing their personal information does not have the measures in place to prevent and correct errors in the data (Smith et al. 1996). This dimension may not be relevant in all consumer cloud contexts, but issues around controlling data flows which are inherent in the cloud may cause concern around organisations' ability to track information, and as a result their capabilities to identify and remedy errors.

The Control dimension focuses on individuals' concerns regarding the lack of control they have over their personal information (Malhotra et al. 2004). Issues around control over data has been highlighted as an important cloud privacy issue that warrants exploration (Sun et al. 2011; Pearson and Benameur 2010). The Awareness dimension centres around individuals' concerns regarding their lack of awareness of how an organisation uses and protects their personal information (Malhotra et al. 2004). Awareness represents another core concern in the cloud context, with lack of transparency around where data is stored and the protection mechanisms in place (e.g. Singh et al. 2015). It is important to therefore examine (1) if consumers lack awareness of privacy practices in the cloud and (2) if a lack of awareness heightens concerns for the privacy of one's personal information.

The broader privacy literature offers a rich theoretical base from which the role of privacy in cloud computing can be advanced. Privacy theories are typically discussed from five perspectives-(1) drivers of privacy concern, (2) behavioural consequences, (3) trade-offs, (4) institutional drivers and (5) individual factors ( $\mathrm{Li} 2012$ ). In contrast to the broader literature, the privacy research in the cloud context is relatively nascent. A review of the literature did not identify any studies leveraging theories in four of these five categories. However, two related studies drew on privacy calculus theory (PCT), a theory commonly utilised to understand the tradeoffs between the benefits and the risks associated with the behaviour in question such as information disclosure or using a new technology (Culnan and Armstrong 1999). PCT posits that individuals engage in a cognitive comparison of the benefits and potential negative outcomes which may result from using a certain technology (Culnan and Armstrong 1999). According to this theory, individuals will utilise the technology as long as their perceptions of the benefits outweigh their risk perceptions (Culnan 1993). The first study focused on consumers' willingness to disclose 
information in cloud-based mobile applications and found that privacy concerns reduced willingness to disclose information, whereas perceived usefulness of the apps and perceived trustworthiness both positively influenced willingness to disclose (Nikkhah and Sabherwal 2017), thereby supporting the use of PCT in this context. The second study focused on consumers' intentions to continue use of cloud-based mobile applications and found that security and privacy interventions reduce privacy concerns and increase trust, and privacy and security concerns both indirectly influence willingness to continue to use apps through trust (Nikkhah et al. 2018), furthering support for PCT. These studies support the potential of privacy theories to advance our understanding of the role of privacy in this context and point to the need to further leverage this rich theoretical base.

\subsection{Enhancing Privacy Perceptions in the Cloud}

The focus of much of the privacy literature in the cloud domain has been on technical measures to secure data to enhance security in the hope of negating privacy issues. These are discussed further in Chap. 7 of this book. These studies focus on reviewing the efficacy of measures such as different approaches and anonymisation mechanisms (Sonehara et al. 2011). Recent works have also highlighted important security considerations in emerging cloud contexts such as IoT, stressing the need to consider secure communications, data identification measures, and certification approaches for example (Singh et al. 2015).

Drawing from the existing research in the cloud context and the broader privacy literature, it can be argued that organisations need to address three related consumer perceptions; (1) control (2) awareness and (3) trust. The first two perceptions relate specifically to privacy concern while the third represents a broader perception of the technology (as discussed in detail in Chap. 1). All three consumer perceptions can negatively influence individuals' willingness to adopt new technologies ( Li 2012) and as such, represent an important barrier to the continued success of cloud computing.

Perceived control is a primary concept within the information privacy literature. However, it is important to note that privacy and control are conceptually distinct (Laufer and Wolfe 1977) and negatively correlated. Control is a perception based variable and has been defined as an individual's beliefs in their ability to manage the collection and use of their personal data (Xu et al. 2011). In the cloud context, it has been noted that 
consumers are afforded little or no control over their information (Alashoor 2014). In other contexts, a lack of perceived control can heighten privacy concerns (Dinev and Hart 2004), whereas if perceived control is high, individuals may be empowered to adopt technologies and disclose more personal information (Palmatier and Martin 2019). Closely related to control is consumers' awareness of how their information is protected and used in the cloud. A lack of transparency is a commonly cited issue in the cloud context with many noting that cloud providers should engage in transparent communications to increase consumer awareness of how their personal data is used (Kesan et al. 2013). Awareness not only encompasses understanding of how data is protected, but where data is stored and how it is used.

Trust is often incorporated into privacy studies including those in the cloud context (e.g. Nikkhah et al. 2018). Consumers' beliefs regarding the trustworthiness of an organisation relate to perceptions of the organisation's benevolence, integrity and competence (van der Werff et al. 2019; Bélanger et al. 2002). In privacy contexts, trust often focuses on an individual's willingness to be vulnerable when transacting or sharing personal information with an organisation (McKnight et al. 2002). In the cloud context, research supports the importance of trust in influencing consumers' willingness to use cloud-based mobile applications and the relationship between privacy concern and trust (Nikkhah et al. 2018).

Central to addressing these consumer perceptions is improving organisational communications with consumers and building knowledge. Organisation's current communication efforts largely involve privacy policies. Currently, privacy policies tend to be quite lengthy and difficult to read (Kelley et al. 2010). Indeed, the time to read the privacy policies of all websites visited by an average American Internet user was estimated as 201 hours annually (McDonald and Cranor 2008). Furthermore, when consumers read privacy policies, they often do not understand the contents (Martin 2015). These issues with readability and understandability, as well as lack of user engagement with privacy policies, has led to calls to develop new communication methods which better inform consumers how their information is used (Park et al. 2012). In addition to how organisations communicate, it is important to ensure consumers are equipped with the privacy knowledge needed to interpret these communications. Indeed, gaps in consumers' privacy knowledge and self-efficacy has recently been highlighted as an important area to address in order to empower informed decision making (Crossler and Bélanger 2017). Thus, 
we present three approaches organisations can use to influence consumer perceptions related to privacy in the cloud namely institutional assurances, just-in-time interventions, and building privacy knowledge. The first two approaches directly relate to communication methods and the third approach focuses on building consumers' privacy literacy and as a result their capacity to engage with organisation consumers regarding their privacy practices.

\subsubsection{Institutional Assurances}

Institutional assurances or privacy disclosures are communication efforts from organisations to consumers, regarding the organisation's data privacy practices. Institutional assurances are often heralded as a solution to addressing privacy concerns, improving perceptions of control and enhancing trust beliefs in many contexts (Culnan and Armstrong 1999; Wu et al. 2012). Institutional assurances include privacy policies and visual approaches which combine text and icons such as privacy labels and trust labels. The privacy literature has found effective privacy policies address awareness issues by increasing perceptions of control (Xu et al. 2011) and improving understanding of privacy practices (Kelley et al. 2010). However, the weaknesses inherent in existing privacy policies led to the emergence of the nutritional privacy label (Kelley et al. 2010). In the cloud context, a cloud trust label providing relevant institutional assurances and privacy information has been found to impact decision makers' perceptions of the trustworthiness of cloud service providers (van der Werff et al. 2019). The nutritional label is one possible approach to institutional assurances which could serve as a fruitful avenue for both cloud service providers and organisations leveraging the cloud. This approach should include all information required in GDPR compliant privacy notices and inform consumers of how their data is used, stored, protected, and the controls they can exercise over their data. In addition, the label should address the three dimensions of trust (benevolence, integrity and competence), and the core security considerations in the cloud context. The label approach combines many recommendations for effective communication from the UK Information Commissioner's Office (ICO) including the use of recognisable icons and layering formats (ICO 2017). The content of the label should differ depending on the organisation and whether the label is consumer facing or used to influence perceptions of key decision makers in organisations. Based on findings in the cloud and 
other contexts, these labels may build awareness and strengthen perceptions of control and trustworthiness. Privacy labels are likely to be useful as a communication tool for prospective customers, and should be accessible to existing customers within the application or website settings.

\subsubsection{Just-in-Time Interventions}

In addition to detailed communication approaches such as privacy labels and notices, there is also a need for additional transparent communications with consumers as the need arises. The ICO advocates the use of just-in-time notices to inform consumers of changes in an organisation's privacy practices (ICO 2017). For example, if an organisation plans to migrate to the cloud, they should inform their consumers of this change in a transparent manner. Additional reasons for just-in-time interventions include cases when an additional use arises for personal data and consumer consent is sought, as well as requests for updates to personal information, or requests for more information. In these interventions, organisations should be transparent and focus on explaining why the data is needed. The format of these interventions will vary depending on the level of the change and the technology in question. For mobile applications, a pop-up notification could be utilised to request consumer consent or additional data disclosure. For websites, individuals could be prompted to provide the requested information at log-in. The purpose of just-in-time interventions is similar to the privacy label approach in that they seek to overcome issues with awareness, while reminding consumers of the controls they have and seeking to enhance trust beliefs through transparency.

\subsubsection{Building Privacy Knowledge}

As repeatedly noted throughout this chapter, cloud consumers often lack awareness of how their data is stored and used. In the broader privacy literature, Crossler and Bélanger (2019) advocate the importance of understanding and addressing consumers' privacy knowledge-belief gaps and the need to develop contextualised privacy self-efficacy i.e. individuals' perceptions that they have the knowledge and skills needed to protect the privacy of their data as required. This work builds on findings around the privacy paradox, wherein consumers express high privacy concerns but do not engage in behaviours to protect their information privacy (Bélanger and Crossler 2011). In their recent study, Crossler and Bélanger (2019) 
found that context-specific privacy knowledge and privacy self-efficacy influence individuals' privacy-protective behaviours. There is a need for organisations to consider consumers' privacy knowledge and self-efficacy both for potential and existing customers. Any communication, be it a privacy label or app notification regarding privacy should consider the consumers' knowledge, and be framed in ways which enhance their knowledge as opposed to obfuscate improper practices. In addition, organisations should provide supplementary information and resources which empower consumers to develop their privacy knowledge and self-efficacy. It is argued that this level of transparency will heighten perceptions of control and trustworthiness while building consumers' privacy self-efficacy and thereby facilitating informed decision making.

\subsection{Future Research Directions}

As discussed earlier, consumer perceptions of privacy are influenced by past experience and the context in question ( $\mathrm{Li} 2011)$. As such, pertinent privacy issues are likely to vary across different cloud contexts (Pearson 2012). At a high level, more privacy research is required that focuses on consumer perceptions of privacy in the cloud in general, among different cloud service provision models, in public/private cloud settings, and in different domains such as IoT. Table 4.2 below outlines a number of potentially fruitful directions for research that may enrich our understanding of privacy in the cloud. As per Li (2012), relevant theories popularised in other privacy contexts are listed alongside each area. These research directions represent an initial step in unravelling the role of the complex privacy construct in this multifaceted and evolving context.

\subsection{Concluding Remarks}

The need to address privacy concerns in order to ensure the success of new information technologies has been argued in the broader privacy literature (Hong and Thong 2013). The importance of addressing privacy and security in the cloud is also well established (Wood 2012). However, literature focused on understanding consumer perceptions regarding privacy in the cloud is still emerging. This chapter argues for the need to move beyond technical solutions which address security first and privacy second, towards a focus on understanding and addressing the privacy perceptions of consumers. Given the proliferation of cloud computing, the potential privacy 
Table 4.2 Future research directions

\begin{tabular}{|c|c|c|c|}
\hline Focus & Areas of focus & Guiding theories & Rationale \\
\hline $\begin{array}{l}\text { Consumer } \\
\text { privacy } \\
\text { perceptions }\end{array}$ & $\begin{array}{l}\text { - Examining the } \\
\text { Antecedents to privacy } \\
\text { concern across } \\
\text { differing cloud } \\
\text { applications. } \\
\text { - Unravelling the } \\
\text { outcomes of privacy } \\
\text { concern } \\
\text { in different contexts } \\
\text { including adoption, } \\
\text { continuance and } \\
\text { disclosure behaviours. } \\
\text { - Further unravelling the } \\
\text { trade-offs between } \\
\text { perceived benefits and } \\
\text { risks in different cloud } \\
\text { domains. } \\
\text { Examining the role of } \\
\text { important privacy- } \\
\text { related } \\
\text { constructs including } \\
\text { trust and risk. }\end{array}$ & $\begin{array}{l}\text { - Privacy calculus } \\
\text { theory } \\
\text { - Social contract } \\
\text { theory } \\
\text { - Protection } \\
\text { Motivation theory }\end{array}$ & $\begin{array}{l}\text { Much of the privacy } \\
\text { literature in other } \\
\text { contexts follows the } \\
\text { APCO model } \\
\text { developed by Smith } \\
\text { et al. (2011) to } \\
\text { explore the } \\
\text { antecedents, privacy } \\
\text { concerns and } \\
\text { outcomes in a given } \\
\text { context. Little is } \\
\text { known about the } \\
\text { important drivers of } \\
\text { concern, dimensions } \\
\text { of concern or } \\
\text { outcomes in the } \\
\text { cloud context. }\end{array}$ \\
\hline $\begin{array}{l}\text { Effectiveness } \\
\text { of } \\
\text { institutional } \\
\text { assurances }\end{array}$ & $\begin{array}{l}\text { - Developing privacy } \\
\text { labels and just-in-time } \\
\text { interventions for } \\
\text { different cloud } \\
\text { applications and } \\
\text { customers e.g. end } \\
\text { users and business } \\
\text { decision makers. } \\
\text { - Examining the } \\
\text { influence of these } \\
\text { assurances on potential } \\
\text { consumers' perceptions } \\
\text { of privacy and trust. } \\
\text { - Examining the } \\
\text { influence of these } \\
\text { assurances on existing } \\
\text { customers perceptions } \\
\text { and willingness to } \\
\text { continue use. }\end{array}$ & $\begin{array}{l}\text { - Communication } \\
\text { privacy management } \\
\text { theory } \\
\text { - Procedural fairness } \\
\text { theory }\end{array}$ & $\begin{array}{l}\text { The potential of } \\
\text { institutional } \\
\text { assurances to } \\
\text { influence consumer } \\
\text { perceptions and } \\
\text { behaviours is } \\
\text { documented in other } \\
\text { contexts. There is a } \\
\text { need to unravel their } \\
\text { effectiveness in the } \\
\text { cloud context given } \\
\text { the breadth of } \\
\text { applications and } \\
\text { technologies relying } \\
\text { on the cloud to some } \\
\text { degree to deliver } \\
\text { services. }\end{array}$ \\
\hline
\end{tabular}


Table 4.2 (continued)

\begin{tabular}{|c|c|c|c|}
\hline Focus & Areas of focus & Guiding theories & Rationale \\
\hline $\begin{array}{l}\text { Role of } \\
\text { regulation }\end{array}$ & $\begin{array}{l}\text { - Examining consumer } \\
\text { perceptions of } \\
\text { regulatory protections } \\
\text { in the cloud context. } \\
\text { - Investigating } \\
\text { regulatory expectations } \\
\text { across cultures and } \\
\text { cloud contexts. }\end{array}$ & $\begin{array}{l}\text { - Regulatory focus } \\
\text { theory }\end{array}$ & $\begin{array}{l}\text { The issue of data } \\
\text { location is a primary } \\
\text { concern in the cloud } \\
\text { context as this has } \\
\text { implications for } \\
\text { regulation. In } \\
\text { addition, perceptions } \\
\text { regarding regulation } \\
\text { has been found to } \\
\text { influence privacy in } \\
\text { other contexts (Li } \\
\text { 2011). Little is } \\
\text { known in terms of } \\
\text { consumers' } \\
\text { regulation knowledge } \\
\text { and expectations in } \\
\text { the cloud context. }\end{array}$ \\
\hline $\begin{array}{l}\text { Privacy and } \\
\text { trust repair }\end{array}$ & $\begin{array}{l}\text { - Examine the impacts of } \\
\text { cloud privacy breaches } \\
\text { on consumer } \\
\text { perceptions regarding } \\
\text { the cloud generally and } \\
\text { the affected } \\
\text { organisation. } \\
\text { - Explore the efficacy of } \\
\text { breach responses in } \\
\text { rebuilding trust and } \\
\text { privacy perceptions }\end{array}$ & $\begin{array}{l}\text { - Psychological } \\
\text { contract breach } \\
\text { - Communication } \\
\text { privacy management } \\
\text { theory }\end{array}$ & $\begin{array}{l}\text { The growth of } \\
\text { privacy breaches in } \\
\text { the cloud has been } \\
\text { widely publicised. It } \\
\text { is important to } \\
\text { explore how these } \\
\text { incidents influence } \\
\text { consumer } \\
\text { perceptions and how } \\
\text { organisations can } \\
\text { recover. }\end{array}$ \\
\hline $\begin{array}{l}\text { Building } \\
\text { privacy } \\
\text { knowledge }\end{array}$ & $\begin{array}{l}\text { - Explore consumers } \\
\text { existing privacy } \\
\text { knowledge and } \\
\text { self-efficacy in different } \\
\text { cloud contexts. } \\
\text { - Examine the efficacy of } \\
\text { different knowledge } \\
\text { and self-efficacy } \\
\text { building approaches. } \\
\text { - Explore the } \\
\text { relationship between } \\
\text { self-efficacy, privacy } \\
\text { concern and behaviours } \\
\text { in different cloud } \\
\text { contexts. }\end{array}$ & $\begin{array}{l}\text { - Self-efficacy theories } \\
\text { - Information- } \\
\text { Motivation-Belief } \\
\text { theory }\end{array}$ & $\begin{array}{l}\text { Consumers lack of } \\
\text { awareness of how } \\
\text { their data is used in } \\
\text { the cloud context } \\
\text { coupled with the } \\
\text { growth of cloud data } \\
\text { breaches point to the } \\
\text { need to understand } \\
\text { and develop privacy } \\
\text { knowledge and } \\
\text { self-efficacy among } \\
\text { consumers. As a } \\
\text { result, it is important } \\
\text { to empirically explore } \\
\text { the efficacy of any } \\
\text { such knowledge } \\
\text { building efforts. }\end{array}$ \\
\hline
\end{tabular}


implications span multiple industries, and privacy may pose different challenges for each industry or application. Proactive approaches to communicate with consumers such as privacy labels can be useful in addressing privacy concerns, enhancing perceptions of control and building trust beliefs. In addition, efforts are needed to build the privacy literacy and self-efficacy of consumers in this context. The recommendations presented in this chapter emphasises the importance of organisations proactively understanding and positively influencing consumer privacy perceptions, over and above the compliance with legal requirements such as the GDPR. It is hoped that this chapter provides some useful recommendations for practice and presents some interesting avenues for research in this domain.

\section{REFERENCES}

Alashoor, T. (2014). Cloud Computing: A Review of Security Issues and Solutions. International Journal of Cloud Computing, 3(3), 228-244.

Alashoor, T., Fox, G., \& Jeff Smith, H. (2017). The Priming Effect of Prominent IS Privacy Concerns Scales on Disclosure Outcomes: An Empirical Examination. Pre-ICIS Workshop on Information Security and Privacy.

Bélanger, F., \& Crossler, R. E. (2011). Privacy in the Digital Age: A Review of Information Privacy Research in Information Systems. MIS Quarterly, 35(4), 1017-1042.

Bélanger, F., Hiller, J. S., \& Smith, W. J. (2002). Trustworthiness in Electronic Commerce: The Role of Privacy, Security, and Site Attributes. The Journal of Strategic Information Systems, 11(3-4), 245-270.

Crossler, R. E., \& Bélanger, F. (2017). The Mobile Privacy-Security Knowledge Gap Model: Understanding Behaviors. Proceedings of the 50th Hawaii International Conference on System Sciences.

Crossler, R. E., \& Bélanger, F. (2019). Why Would I Use Location-Protective Settings on My Smartphone? Motivating Protective Behaviors and the Existence of the Privacy Knowledge-Belief Gap. Information Systems Research, 30(3), 995-1006.

Culnan, M. J. (1993). "How Did They Get My Name?" An Exploratory Investigation of Consumer Attitudes toward Secondary Information Use. MIS Quarterly, 17, 341-363.

Culnan, M. J., \& Armstrong, P. K. (1999). Information Privacy Concerns, Procedural Fairness, and Impersonal Trust: An Empirical Investigation. Organization Science, 10(1), 104-115. 
Dinev, T., \& Hart, P. (2004). Internet Privacy Concerns and Their AntecedentsMeasurement Validity and a Regression Model. Behaviour \& Information Technology, 23(6), 413-422.

Dinev, T., \& Hart, P. (2006). An Extended Privacy Calculus Model for E-Commerce Transactions. Information Systems Research, 17(1), 61-80.

DivvyCloud. (2020). 2020 Cloud Misconfigurations Report. Retrieved from https://divvycloud.com/misconfigurations-report-2020/

Forbes. (2020). Beware-This Open Database On Google Cloud 'Exposes 200 Million Americans': Are You at Risk?. Retrieved from https://www.forbes. com/sites/zakdoffman/2020/03/20/stunning-new-google-cloudbreach-hits-200-million-us-citizens-check-here-if-youre-now-atrisk/\#1737e9528587

Fauzi, A. A. C., Noraziah, A., Herawan, T., \& Zin, N. M. (2012, March). On cloud computing security issues. In Asian Conference on Intelligent Information and Database Systems (pp. 560-569). Springer, Berlin: Heidelberg.

Gartner. (2019). Gartner Forecasts Worldwide Public Cloud Revenue to Grow $17 \%$ in 2020. Retrieved from https://www.gartner.com/en/newsroom/ press-releases/2019-11-13-gartner-forecasts-worldwide-public-cloud-revenue-to-grow-17-percent-in-2020

Hong, W., \& Thong, J. Y. L. (2013). Internet Privacy Concerns: An Integrated Conceptualization and Four Empirical Studies. MIS Quarterly, 37( 1), 275-298.

ICO. (2017). Privacy Notices, Transparency and Control. A Code of Practice on Communicating Privacy Information to Individuals. Retrieved from https:// ico.org.uk/for-organizations/guide-to-dataprotection/privacy-notices-transparencyand-control/

ISO 27001. (2005). Information Security Management-Specification with Guidance for Use.

Kelley, P. G., Cesca, L., Bresee, J., \& Cranor, L. F. (2010). Standardizing Privacy Notices: An Online Study of the Nutrition Label Approach. Proceedings of the SIGCHI Conference on Human Factors in Computing Systems, pp. 1573-1582.

Kesan, J. P., Hayes, C. M., \& Bashir, M. N. (2013). Information Privacy and Data Control in Cloud Computing: Consumers, Privacy Preferences, and Market Efficiency. Washington and Lee Law Review, 70, 341.

Laufer, R. S., \& Wolfe, M. (1977). Privacy as a Concept and a Social Issue: A Multidimensional Developmental Theory. Journal of Social Issues, 33(3), 22-42.

Li, Y. (2011). Empirical Studies on Online Information Privacy Concerns: Literature Review and an Integrative Framework. CAIS, 28, 28.

Li, Y. (2012). Theories in Online Information Privacy Research: A Critical Review and an Integrated Framework. Decision Support Systems, 54(1), 471-481.

Lowry, P. B., Dinev, T., \& Willison, R. (2017). Why Security and Privacy Research Lies at the Centre of the Information Systems (IS) Artefact: Proposing a Bold Research Agenda. European Journal of Information Systems, 26(6), 546-563. 
Malhotra, N. K., Kim, S. S., \& Agarwal, J. (2004). Internet Users' Information Privacy Concerns (IUIPC): The Construct, the Scale and a Causal Model. Information Systems Research, 15(4), 336-355.

Martin, K. (2015). Privacy Notices as Tabula Rasa: An Empirical Investigation Into How Complying with a Privacy Notice is Related to Meeting Privacy Expectations Online. Journal of Public Policy \& Marketing, 34(2), 210-227.

McDonald, A. M., \& Cranor, L. F. (2008). The Cost of Reading Privacy Policies. Information System: A Journal of Law and Policy for the Information Society, 4(3), 543-568.

McKnight, D. H., Choudhury, V., \& Kacmar, C. (2002). Developing and Validating Trust Measures for e-commerce: An Integrative Typology. Information Systems Research, 13(3), 334-359.

Nikkhah, H. R., \& Sabherwal, R. (2017). Mobile Cloud-Computing Applications: A Privacy Cost-Benefit Model. Proceedings of the Twenty-third Americas Conference on Information Systems, Boston.

Nikkhah, H. R., Grover, V., \& Sabherwal, R. (2018). Why Do Users Continue to Use Mobile Cloud Computing Applications? A Security-Privacy. Proceedings of the 13th Pre-ICIS Workshop on Information Security and Privacy, Vol. 1.

Palmatier, R. W., \& Martin, K. D. (2019). The Intelligent Marketer's Guide to Data Privacy. Springer.

Paquette, S., Jaeger, P. T., \& Wilson, S. C. (2010). Identifying the Security Risks Associated with Governmental Use of Cloud Computing. Government Information Quarterly, 27(3), 245-253.

Park, Y. J., Campbell, S. W., \& Kwak, N. (2012). Affect, Cognition and Reward: Predictors of Privacy Protection Online. Computers in Human Behavior, 28(3), 1019-1027.

Pearson, S. (2012). Privacy, Security and Trust in Cloud Computing, pp. 1-57. Retrieved from https://www.hpl.hp.com/techreports/2012/HPL-201280Rl.pdf

Pearson, S., \& Benameur, A. (2010, November). Privacy, Security and Trust Issues Arising from Cloud Computing. 2010 IEEE Second International Conference on Cloud Computing Technology and Science (pp. 693-702). IEEE.

Ramireddy, S., Chakraborty, R., Raghu, T. S., \& Rao, H. R. (2010). Privacy and Security Practices in the Arena of Cloud Computing-A Research in Progress. In AMCIS, p. 574.

Scholtz, B., Govender, J., \& Gomez, J. M. (2016). Technical and Environmental Factors Affecting Cloud Computing Adoption in the South African Public Sector. CONF-IRM, p. 16.

Senarathna, I., Yeoh, W., \& Warren, M. (2014). Security and Privacy Concerns for Australian SMEs Cloud Adoption. WISP 2014 Proceedings.

Senarathna, I., Yeoh, W., Warren, M., \& Salzman, S. (2016). Security and Privacy Concerns for Australian SMEs Cloud Adoption: Empirical Study of 
Metropolitan vs Regional SMEs. Australasian Journal of Information Systems, 20, 1-20.

Shropshire, J., Campbell, M., \& Bob, S. (2015). Overcoming Privacy Challenges in Mobile-Cloud Computing. SAIS 2015 Proceedings, p. 28

Singh, J., et al. (2015). Twenty Security Considerations for Cloud-Supported Internet of Things. IEEE Internet of things Journal, 3(3), 269-284.

Smith, H. J., Dinev, T., \& Xu, H. (2011). Information Privacy Research: An Interdisciplinary Review. MIS Quarterly, 35(4), 989-1016.

Smith, H. J., Milberg, S. J., \& Burke, S. J. (1996). Information Privacy: Measuring Individuals' Concerns about Organizational Practices. MIS Quarterly, 20, 167-196.

Son, J.-Y., \& Kim, S. S. (2008). Internet Users' Information Privacy-Protective Responses: A Taxonomy and a Nomological Model. MIS Quarterly, $32(3), 503-529$.

Sonehara, N., Echizen, I., \& Wohlgemuth, S. (2011). Isolation in Cloud Computing and Privacy-Enhancing Technologies. Business \& Information Systems Engineering, 3(3), 155.

Subashini, S., \& Kavitha, V. (2011). A Survey on Security Issues in Service Delivery Models of Cloud Computing. Journal of Network and Computer Applications, 34(1), 1-11.

Sun, D., Chang, G., Sun, L., \& Wang, X. (2011). Surveying and Analysing Security, Privacy and Trust Issues in Cloud Computing Environments. Procedia Engineering, 15, 2852-2856.

van der Werff, L., Fox, G., Masevic, I., Emeakaroha, V. C., Morrison, J. P., \& Lynn, T. (2019). Building Consumer Trust in the Cloud: An Experimental Analysis of the Cloud Trust Label Approach. Journal of Cloud Computing, 8(1), 6.

Warren, S. D., \& Brandeis, L. D. (1890). The Right to Privacy. Harvard Law Review, 193-220.

Westin, A. (1967). Privacy and Freedom. New York: Atheneum.

Whittaker, Z. (2020). Marriott Says 5.2 Million Guest Records Were Stolen in Another Data Breach. TechCrunch. Retrieved from https://techcrunch. com/2020/03/31/marriott-hotels-breached-again/

Wood, K. (2012). Exploring Security Issues in Cloud Computing. UKAIS.

Wu, K.-W., Huang, S. Y., Yen, D. C., \& Popova, I. (2012). The Effect of Online Privacy Policy on Consumer Privacy Concern and Trust. Computers in Human Behavior, 28(3), 889-897.

$\mathrm{Xu}, \mathrm{H}$, et al. (2011). Information Privacy Concerns: Linking Individual Perceptions with Institutional Privacy Assurances. Journal of the Association for Information Systems, 12(12), 798-824. 
Open Access This chapter is licensed under the terms of the Creative Commons Attribution 4.0 International License (http://creativecommons.org/licenses/ by $/ 4.0 /$ ), which permits use, sharing, adaptation, distribution and reproduction in any medium or format, as long as you give appropriate credit to the original author(s) and the source, provide a link to the Creative Commons licence and indicate if changes were made.

The images or other third party material in this chapter are included in the chapter's Creative Commons licence, unless indicated otherwise in a credit line to the material. If material is not included in the chapter's Creative Commons licence and your intended use is not permitted by statutory regulation or exceeds the permitted use, you will need to obtain permission directly from the copyright holder. 